\title{
Differentiation of Mesenchymal Stem Cells into Hepatocyte-Like Cells by Autologous Serum after Radiofrequency Ablation of Liver Tumor
}

\author{
Yi Yang, Xi Chen, Tao Wu, Xin Xu, Gang Cao, Hua Li, Yiming Li* \\ Department of General Surgery, Second Hospital of Xi'an Jiaotong University, Xi'an, China \\ Email: yangyi2002163@163.com, chenxi@sina.com,wutao228@163.com, xuxin72722@126.com, \\ paul5318@sina.com, ongig@sina.com, ${ }^{*}$ liyiming2003@sina.cn
}

Received 7 July 2014; revised 5 August 2014; accepted 2 September 2014

Copyright (C) 2014 by authors and Scientific Research Publishing Inc.

This work is licensed under the Creative Commons Attribution International License (CC BY). http://creativecommons.org/licenses/by/4.0/

(c) (i) Open Access

\begin{abstract}
Mesenchymal stem cells (MSCs) have been shown to differentiate into liver cells in serum of partresection liver, but it was hardly feasible in clinical use. Our studies revealed that MSCs could differentiate into hepatocyte-like cells in autologous serum after radiofrequency ablation (RFA) therapy of the liver tumor. Rabbits with liver tumor subsequently treated with RFA therapy. Serum was collected from those rabbits before RFA therapy and 72 hours after RFA therapy. MSCs were isolated from each rabbit's bone marrow and cultured in DMEM medium containing the following different supplements: $\mathbf{3 0 \%}$ fetal calf serum (FCS group), $\mathbf{3 0 \%}$ rabbit autologous serum (AS group) or $30 \%$ autologous serum after RFA treatment of the liver tumor (ASRF group), observed by electron microscopy, flow cytometry, immunofluorescence. Seven days later, most of the spindle-shaped MSCs in the ASRF group transformed into polygon or round-shaped cells resembling hepatocytes, and the percentage in S/G2/M phase was higher than in the FCS or AS groups. Fourteen days later, slender microvilli, cell-cell junction structures and cholangiole emerged in the cells belonging to the ASRF group, the expression of albumin and CK18 was observed only in the differentiated cells from the ASRF group. These changes were not observed in the FCS group or the AS group. This study may provide a potential cell source and culture process for clinical application in liver injury treatment.
\end{abstract}

\section{Keywords}

Autologous Serum, Hepatocyte-Like Cell, Liver Tumor, Mesenchymal Stem Cell, Radiofrequency Ablation

\footnotetext{
${ }^{*}$ Corresponding author.
}

How to cite this paper: Yang, Y., Chen, X., Wu, T., Xu, X., Cao, G., Li, H. and Li, Y.M. (2014) Differentiation of Mesenchymal Stem Cells into Hepatocyte-Like Cells by Autologous Serum after Radiofrequency Ablation of Liver Tumor. Stem Cell Discovery, 4, 99-106. http://dx.doi.org/10.4236/scd.2014.44011 


\section{Introduction}

Expanded bone marrow-derived MSCs possess the potential to differentiate into hepatocyte-like cells [1]-[3] and can therefore be used in cell-based therapy for various liver diseases [4]. In vitro expansion of MSCs has mainly been achieved in the presence of $30 \%$ FCS. To date, intravenous infusion of such cells has been considered relatively safe. However, unfavorable immune responses toward FCS have been reported, [5] and these responses are possibly due to contamination from proteins in the serum. Other possible risks of FCS include viral or bacterial infections or prion infection [6]. For these reasons, alternative culture protocols that replace FCS with autologous serum have been suggested.

Although the detailed mechanisms that govern the differentiation of MSCs remain unclear, there is accumulating evidence that bone MSCs may participate in liver regeneration after partial hepatectomy or $\mathrm{CCl}_{4}$ injury [7]. Various growth and differentiation factors, such as cytokines in serum, may play an important role in this differentiation process [8].

During the past few years, RFA has been applied successfully in the field of surgical oncology. RFA offers an alternative local treatment to in-operable hepatic tumors, and its therapeutic effects, including a 5-year survival rate, are similar to that of the partial hepatectomy [9]. This indicates that bone MSCs obtained after RFA therapy of liver tumors may participate in liver regeneration.

In the present study using rabbits, we investigated the potential of bone MSCs to differentiate into hepatocyte-like cells under the direct influence of autologous serum obtained after RFA therapy of liver tumor.

\section{Materials and Methods}

\subsection{Experimental Animal}

Eight to twelve week-old male New Zealand White rabbits with a body weight of 1.5 - $2.0 \mathrm{~kg}$ were obtained from the Laboratory Animal Unit of Xi'an Jiaotong University (Certificate No. shannxi 08-005). All animals used in this study were housed in a climate-controlled $\left(21^{\circ} \mathrm{C}\right)$ room under a 12-h light-dark cycle and were given tap water. All operations were performed under general anesthesia using sterile surgical technique and all animals received humane care in accordance with the principles and guidelines prepared by the National Institutes of Health, China.

\subsection{Radiofrequency Oncotherapy in a Transplanted Liver Tumor Model and Collection of Autologous Serum}

Under aseptic conditions, animals were anesthetized with $40 \mathrm{mg} / \mathrm{kg}$ ketamine and $12.5 \mathrm{mg} / \mathrm{kg}$ chlorpromazine, and their abdomens were dissected to expose the liver. A $1 \mathrm{~mm}^{3}$ piece of VX2 tumor was surgically implanted into Glisson's capsule and the wound was closed. After three weeks, an ultrasound was performed on the inoculated area to verify the establishment of the transplanted liver tumor. RFA oncotherapy was performed on the animals according to the method of Merkle EM [10]. The radiofrequency current was delivered by using a Radiofrequency Generator 2000 and a 10 Tsim anchor-shaped electrode (Radio Therapeutic ${ }^{\mathrm{TM}}$ Corporation, Mountain View, CA, USA). RFA was performed by placing the electrode needle at the center of the hepatic tumor and expanding outward to a diameter of 10 - $20 \mathrm{~mm}$ to inactivate the hepatic tumor and $40 \%$ of hepatic tissues. During the procedure, the applied current, power output, and tissue impedance were monitored constantly. After RF exposure, the cooling system was stopped to measure the local tissue temperature. When the temperature exceeded $60^{\circ} \mathrm{C}$, the ablation was considered adequate. At the end of the procedure, the generator was reactivated while the RF electrode was withdrawn to ablate the needle track and prevent tumor seeding and the wound was closed. Serum samples were collected from rabbits immediately before and 72 hours after radiofrequency therapy of the liver tumor. Whole blood was collected from arteria carotis into $10 \mathrm{ml}$ serum monovettes containing beads coated with kaolin clotting activator and stored at $4^{\circ} \mathrm{C}$ overnight. Subsequently, the blood was centrifuged at $3000 \mathrm{rpm}$ for 5 minutes and the upper layer of the serum sample was aliquoted and stored at $-20^{\circ} \mathrm{C}$ for future analysis.

\subsection{Isolation and Culture of Bone MSCs}

MSCs were isolated from the rabbit bone marrow aspirates according to the method of Lennon DP [11]. New 
Zealand white rabbits were intravenously anesthetized via the ear vein with 2-chlorocyclohexanone (40 mg/kg). $5 \mathrm{ml}$ of bone marrow was collected from the tibia using a 12-gauge puncture needle and 10-ml syringe (containing $3000 \mu \mathrm{g} / \mathrm{ml}$ heparin $0.2 \mathrm{ml}$ ). The bone marrow was then added to a tube containing the same volume of lymphocyte separation medium (1.073 g/ml, Hyclone Laboratories, Logan, UT, USA) and centrifuged at 1500 rpm for 20 minutes. The ivory-white nuclear cell layer was drawn out and inoculated in $25 \mathrm{ml}$ culture bottles at a cell density of $1 \times 10^{6} \mathrm{cells} / \mathrm{ml}$. After the differential adherence method was used to discard the non-adherent cells, the adherent cells were digested by parenzyme and cultured in DMEM (Hyclone Laboratories, Logan, UT, USA) containing: $1 \mathrm{~g} / \mathrm{l}$ glucose, 1\% penicillin/streptomycin, and either selected 30\% FCS (Hyclone Laboratories, Logan, UT, USA) (FCS group), 30\% autologous serum (AS group), or 30\% autologous serum after radiofrequency ablation of the liver tumor (ASRF group) in 12-well plates at a density of $1 \times 10^{6}$ cells per well at $37^{\circ} \mathrm{C}$ in a humidified atmosphere containing $5 \% \mathrm{CO}_{2}$. After three days, non-adherent cells were washed out and the adherent MSCs were further expanded with the medium described above and fed every three days. At $80 \%$ confluency, cells were trypsinized and seeded at low density for further expansion.

\subsection{Morphological and Microstructural Observation by Electron Microscopy}

After 7 and 14 days of culture, cells were washed with PBS (pH 7.5), fixed in 2.5\% glutaraldehyde in $100 \mathrm{~mm}$ sodium cacodylate buffer for $48 \mathrm{hr}$, post-fixed in 1\% osmium tetroxide, dehydrated in graded alcohols, and embedded in Epon. Ultrathin sections were stained with uranyl acetate and lead citrate and viewed using a Zeiss EM 9-A Electron Microscope (Zeiss, Oberkochen, Germany).

\subsection{Analysis of Cell Cycle}

The cell cycle was assessed by flow cytometry after 14 days of culture according to the method of Hulspas R. et al. [12]. Cells were harvested by trypsin digestion, washed with PBS, fixed in 70\% alcohol, and re-suspended in $1.0 \mathrm{ml}$ hypotonic PI solution in polypropylene tubes. The PI fluorescence of individual nuclei was measured by BD FACSCalibur Flow Cytometer (Becton Dickinson, Heidelberg, Germany) with an argon laser (488 nm) and emission filter $585 \pm 42 \mathrm{~nm}$. For each analysis, 10,000 events were recorded.

\subsection{Detection of Markers of Hepatocytes with Immunofluorescence}

MSCs were cultured on coverslips in six-well plates until confluent and washed three times with normal saline, $2 \%$ saponin/PBS and PBS (pH 7.2), then fixed with paraformaldehyde and treated with $0.1 \%$ Triton X-100. Cells were then incubated overnight at $4^{\circ} \mathrm{C}$ with primary antibody (1:100, Boster Company, Wuhan, China) against albumin and CK18. After washing with PBS, the cells were then incubated with FITC-conjugated and TRITC-conjugated goat anti-rabbit IgG (Boster Company, Wuhan, China) at $37^{\circ} \mathrm{C}$ for $1 \mathrm{hr}$. Immunofluorescence staining was viewed with a Leica TCS/SP2 laser scanning confocal microscope (Leica, Heidelberg, Germany) and Imaris.v4.0.6 software (Bitplane, Washington DC, USA). The excitation and emission wavelengths for FITC/TRITC were $492 \mathrm{~nm}$ and $520 \mathrm{~nm}$, respectively. To exclude the possibility that the trafficking of proteins was affected by the GFP fusion itself, immunofluorescence staining was conducted as previously described [13].

\subsection{Statistical Analysis}

All results were expressed as means \pm SD. The data was analyzed for statistical significance using Student's $t$-test. A P-value of less than 0.05 was considered significant.

\section{Results}

\subsection{Morphology and Microstructure}

After seven days in culture in the 30\% autologous serum obtained after radiofrequency ablation (ASRF group), most of the spindle-shaped MSCs were rounded and resembled hepatocyte-like cells, whereas such a change was not observed in the cells cultured in 30\% fetal calf serum (FCS group) or in 30\% rabbit autologous serum (AS group) (Figure 1(a)). Fourteen days after culture, expanded MSCs in the FCS group showed the general subcellular morphological characteristics of normal MSCs (Figures 1(a)-(d)). Most nuclei of these cells contained euchromatin and 1 - 2 nucleoli. As frequently seen in malignant cells, the nuclei had indentations and few 
lipid droplets present, and all cell organ elles (including lysosomes and mitochondria) were noticeably small (Figure 2(a)). Few or no slender microvilli, cell-cell junction structures or cholangiole were observed on the cell surface (Figure 2(b)). The morphological characteristics of MSCs in AS group were similar to those in the FCS group (Figure 2(c) \& Figure 2(d)). In contrast, MSCs cultured in ASRF group showed subcellular morphological

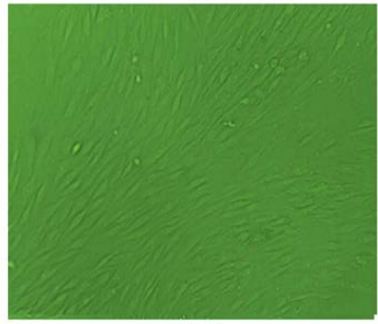

(a)

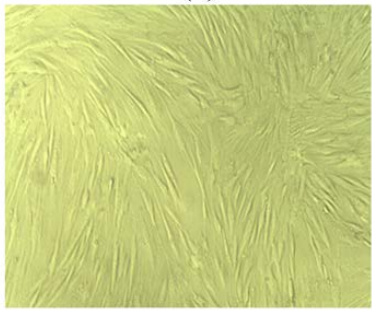

(c)

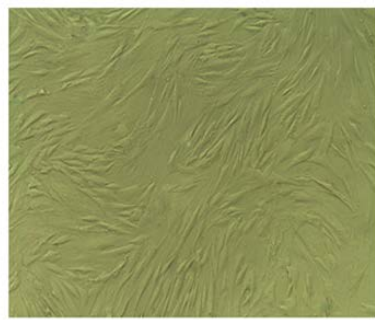

(b)

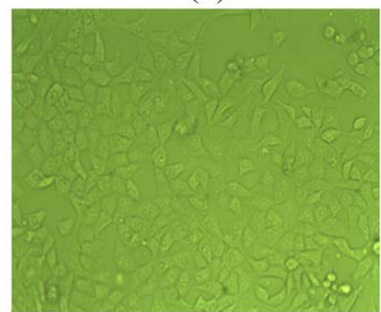

(d)

Figure 1. (a) P0 MSCs in 1 week. Original magnification 10×; (b) P4 MSCs in FCS group 2 weeks. Original magnification 20×; (c) P4 MSCs in AS group 2 weeks. Original magnification 20×; (d) P4 MSCs in ASRF group 2 weeks. Original magnification $20 \times$.

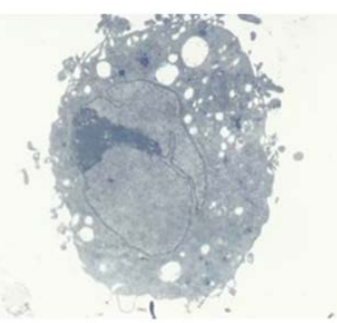

(a)

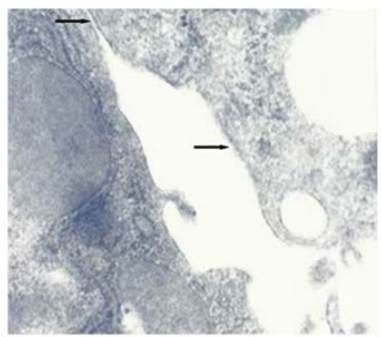

(c)

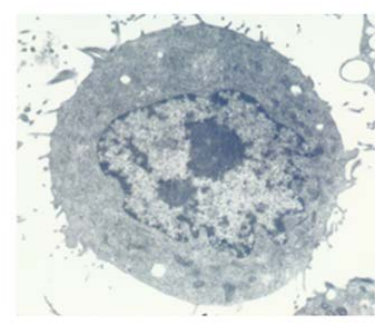

(b)

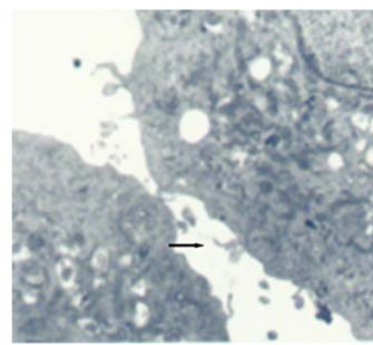

(d)

Figure 2. MSCs cultured for 14 days. (a) The morphological characteristics in the FCS group. Original magnification 3500×; (b) The morphological characteristics in the AS group. Original magnification 5000×; (c) Slender microvilli, cell-cell junction structures and cholangiole emerged in the FCS group (arrows). Original magnification 30,000×. MSCs cultured in AS for 14 days; (d) Slender microvilli, cell-cell junction structures in the AS group (arrows). Original magnification 25,000×. 
characteristics similar to hepatocytes: the MSC's karyoplasmic ratio diminished and had focus tendencies (Figure 3(a)). Free ribosomes (Ri) could be seen dispersed in the cell sap and rough endoplasmic reticulum (RER). Also, larger lysosomes and numerous lipid droplets existed, and mitochondria (Mi) increased (Figure 3(b)). Interestingly, cells with typical apoptotic nuclear structures were also occasionally observed in this group. Such cells showed increased cell kytoplasm concentration and electron densities, as well as broken nuclei and the emergence of apoptotic-bodies (Figure 3(c), arrows). Several slender microvilli, cell-cell tight junction (Tj) structures and cholangiole could be seen on the cell surface (Figure 3(d)).

\subsection{Cell Cycle Analysis}

It is apparent from these values that the cell cycle phase distribution of MSCs in the ASRF group is significantly higher than that of the FCS and AS groups ( $<0.01$ for \% S/G2/M, G0/G1, and \% Apoptosis), whereas no significant difference in the cell cycle distribution was found between the FCS and AS groups. See Table 1.

\subsection{Immunofluorescence Characterization}

Indirect immunofluorescence staining for albumin with secondary FITC anti-mouse antibody (green) and for CK18 with secondary TRITC (red) antibody was visualized with a Leica TCS SP2 confocal microscope. Expression of albumin and CK18 could only be observed in the differentiated hepatocyte-like cells in the ASRF group (Figure 4(a) \& Figure 4(b)), whereas no immunofluorescence staining for albumin and CK18 was observed

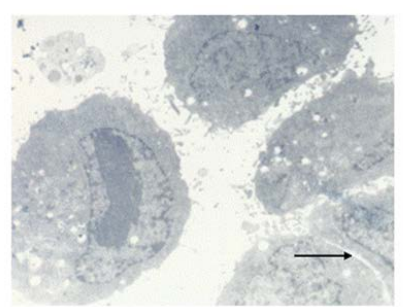

(a)

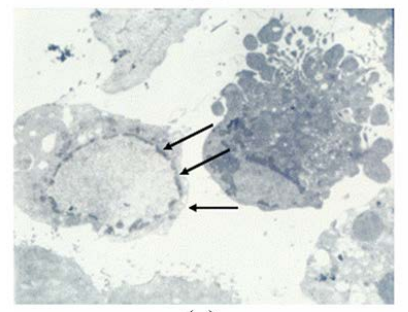

(c)

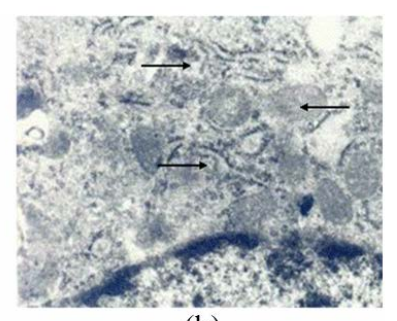

(b)

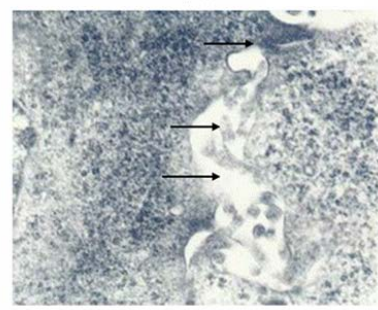

(d)

Figure 3. MSCs cultured in AS after RFA for 14 days. (a) Karyoplasmic ratio diminished. Original magnification 3500×; (b) Subcellular characteristics. Rough endoplasmic reticulum (up arrow), free ribosomes (down arrow) could be seen dispersed in the cell sap and mitochondria (middle arrow) increased .Original magnification 25,000×; (c) Typical apoptotic nuclear structures (arrows). Original magnification 3500×; (d) Cell-cell tight junction structures (up arrow), Slender microvilli (middle arrow) and cholangiole emerged (down arrow). Original magnification 30,000×.

Table 1. Cell cycle of of MSCs in different groups (Mean \pm SD).

\begin{tabular}{cccc}
\hline Group & $\mathrm{S}+\mathrm{G} 2+\mathrm{M}(\%)$ & $\mathrm{G} 1 / \mathrm{G} 2$ & Apoptotic cell (\%) \\
\hline FCS & $22.4 \pm 3.3$ & $1: 2.12$ & 2.3 \\
AS & $27.5 \pm 4.2$ & $1: 2.04$ & 3.5 \\
ASRF & $43.7 \pm 4.7^{\mathrm{a}}$ & $1: 1.83^{\mathrm{a}}$ & $8.7^{\mathrm{a}}$ \\
\hline
\end{tabular}

${ }^{\mathrm{a}} \mathrm{P}<0.05$ vs FCS and ASRF groups. 


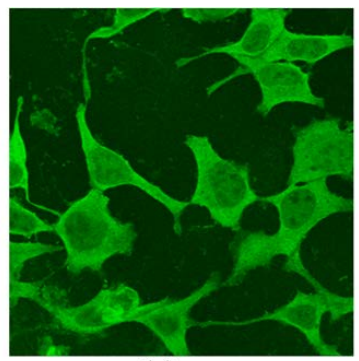

(a)

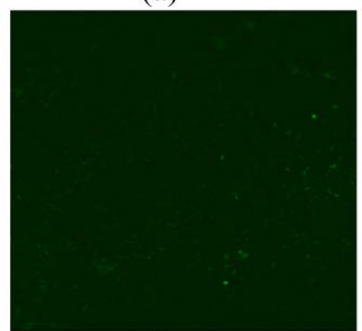

(c)

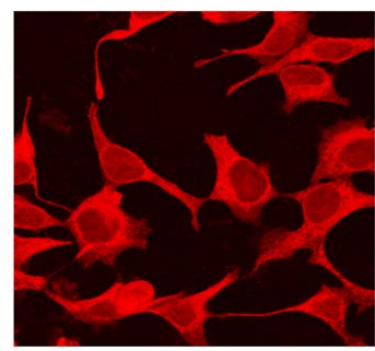

(b)

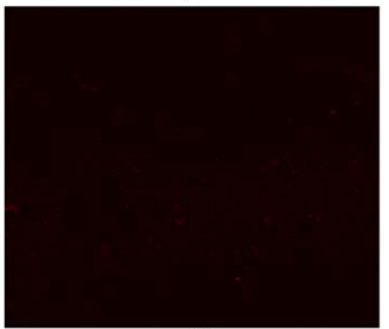

(d)

Figure 4. Immunofluorescence of MSCs cultured for 14 days. (a) Albumin expressed with FITC (green) and (b) CK18 expressed with TRITC (red) in ASRF group. Original magnification 400×; (c) No expression of FITC-labeled albumin and (d) No expression of TRITC-labeled CK18 in the FCS or AS group. Original magnification $400 \times$.

in cultured MSCs from the FCS and AS groups (Figure 4(c) \& Figure 4(d)).

\section{Discussion}

MSCs are multipotent cells that can be isolated from adult bone marrow and can be induced in vitro and in vivo to differentiate into a variety of mesenchymal tissues, including bone, cartilage, tendon, fat, muscle and liver [1] [14]. Accumulating evidence demonstrates the ability of bone MSCs to participate in liver regeneration after partial hepatectomy [15]. MSC-induced mobilization of CD34+ cells has been reported after liver resection in patients with primary liver carcinoma or metastasis [8]. Many growth and differentiation factors including HGF (hepatocyte growth factor), EGF (epidermal growth factor), TNF (tumor necrosis factor), and interleukin have been identified as being involved in this process [16]. For example, HGF has been identified as a mitogen for mature hepatocytes and is considered to be important for the development and regeneration of the liver [17] [18].

Surgical resection still remains the most effective therapeutic approach for the treatment of hepatic tumors. Unfortunately, surgical operation is not feasible for some patients with marked cirrhosis and questionable liver function. RFA offers an alternative local treatment to un-resectable hepatic tumors and has recently been applied successfully in the field of surgical oncology [19]. Resection and RFA combined may play an even more important role in the management of HCC because of the high frequency of multifocal tumors and associated cirrhosis, which limit the applicability of extended resection to multifocal or bilobar HCCs [9]. Ablation of solid tumors with RF results from local resistive heating, which is produced when ions follow the oscillations of the highfrequency alternating electric field. A serious complication of RFA is the reduction of liver parenchymal volume, which may be critical for the metabolic demands of the organism. Whether bone MSCs are able to participate in liver regeneration after RFA of liver tumors is still an issue that needs to be addressed.

The expansion of MSCs in vitro has mainly been achieved in the presence of FCS, which might raise the risks of viral, bacterial and/or prion infection. Culturing MSCs in autologous serum may avoid these risks and retain the multi-lineage potential of MSCs. Thus, culturing MSCs in autologous serum for cell transplantion treatment is considered a promising strategy for the therapy of various liver diseases [3]. Whether bone MSCs can differentiate into hepatocytes in AS after RFA of a liver tumor remains unknown.

In our previous study, we investigated the optimal AS concentration for the expansion of rabbit MSCs [20]. A 
range of gradient concentrations from $1 \%$ to $70 \%$ of AS was applied, and the expansion rate to AS concentration exhibited a positive correlation within $50 \%$. We chose the $30 \%$ AS after RFA therapy of the liver tumor as the suitable concentration for culturing MSCs into hepatocyte-like cells [21]. In the present study, we compared the differentiating effect of the medium supplemented with either FCS, AS or ASRF on cultured MSCs.

Fourteen days after culture, expanded MSCs in FCS and AS showed the general subcellular morphological characteristics of normal MSCs. In contrast, MSCs cultured in ASRF showed morphological characteristics similar to hepatocytes; free ribosomes and lysosomes, numerous lipid droplets, mitochondrial formation, slender microvilli, cell-cell junction structure and cholangiole were observed. These observations demonstrate a remarkable ability of the MSCs to differentiate in the ASRF group. Cell cycle analysis showed that the percentages of cultured MSCs in S/G2/M phase and the ratios of G1 to G2 in ASRF group are higher than those of the FCS and AS groups, indicating that AS after RFA was better for proliferation of MSCs. The higher percentage of apoptotic cells in the ASRF group may be due to some equilibrium mechanism of proliferation or defect something needed unclearly. Albumin is a typical marker of mature hepatocytes, whereas CK18 is expressed in several liver cell types including biliary epithelial cells and hepatic oval cells. The expression of albumin and CK18 was observed only in the differentiated hepatocyte-like cells in the ASRF group. However, the expression of these two markers is not associated with the expression of other hepatocyte markers and this expression does not necessarily demonstrate that these cells differentiated into true hepatocytes. For this purpose, more functional studies in animal models of liver disease are needed.

In conclusion, this study showed that MSCs can be expanded and induced into hepatocyte-like cells using AS after RFA in a rabbit model and this procedure may provide a potential cell source and culture process for clinical application in liver injury repair.

\section{Acknowledgements}

This study was supported “The Fundamental Research Funds for the Central Universities”.

\section{Conflict of Interest}

The authors reported no conflict of interests.

\section{References}

[1] Petersen, B.E., Bowen, W.C., Patrene, K.D., Mars, W.M., Sullivan, A.K., Murase, N., Boggs, S.S., Greenberger, J.S. and Goff, J.P. (1999) Bone Marrow as a Potential Source of Hepatic Oval Cells. Science, 284, 1168-1170. http://dx.doi.org/10.1126/science.284.5417.1168

[2] Hatch, H.M., Zheng, D., Jorgensen, M.L. and Petersen, B.E. (2002) SDF-1alpha/CXCR4: A Mechanism for Hepatic Oval Cell Activation and Bone Marrow Stem Cell Recruitment to the Injured Liver of Rats. Cloning Stem Cells, 4, 339-351. http://dx.doi.org/10.1089/153623002321025014

[3] Lange, C., Bassler, P., Lioznov, M.V., Bruns, H., Kluth, D., Zander, A.R. and Fiegel, H.C. (2005) Hepatocytic Gene Expression in Cultured Rat Mesenchymal Stem Cells. Transplantation Proceedings, 37, 276-279. http://dx.doi.org/10.1016/j.transproceed.2004.11.087

[4] Sharma, A.D., Cantz, T., Manns, M.P. and Ott, M. (2006) The Role of Stem Cells in Physiology, Pathophysiology, and Therapy of the Liver. Stem Cell Reviews, 2, 51-58. http://dx.doi.org/10.1007/s12015-006-0009-8

[5] Tuschong, L., Soenen, S.L., Blaese, R.M., Candotti, F. and Muul, L.M. (2002) Immune Response to Fetal Calf Serum by Two Adenosine Deaminase-Deficient Patients after T Cell Gene Therapy. Human Gene Therapy, 13, 1605-1610. http://dx.doi.org/10.1089/10430340260201699

[6] Will, R.G., Ironside, J.W., Zeidler, M., Cousens, S.N., Estibeiro, K., Alperovitch, A., Poser, S., Pocchiari, M., Hofman, A. and Smith, P.G. (1996) A New Variant of Creutzfeldt-Jakob Disease in the UK. Lancet, 347, 921-925. http://dx.doi.org/10.1016/S0140-6736(96)91412-9

[7] Oyagi, S., Hirose, M., Kojima, M., Okuyama, M., Kawase, M., Nakamura, T., Ohgushi, H. and Yagi, K. (2006) Therapeutic Effect of Transplanting HGF-Treated Bone Marrow Mesenchymal Cells into $\mathrm{CCl}_{4}$-Injured Rats. Journal of Hepatology, 44, 742-748. http://dx.doi.org/10.1016/j.jhep.2005.10.026

[8] De Silvestro, G., Vicarioto, M., Donadel, C., Menegazzo, M., Marson, P. and Corsini, A. (2004) Mobilization of Peripheral Blood Hematopoietic Stem Cells Following Liver Resection Surgery. Hepatogastroenterology, 51, 805-810.

[9] Poon, R.T. (2007) Radiofrequency Ablation Combined with Resection Enhances Chance for Curative Treatment of 
Hepatocellular Carcinoma. Annals of Surgical Oncology, 14, 3299-3300. http://dx.doi.org/10.1245/s10434-007-9567-5

[10] Merkle, E.M., Boll, D.T., Boaz, T., Duerk, J.L., Chung, Y.C., Jacobs, G.H., Varnes, M.E. and Lewin, J.S. (1999) MRI-Guided Radiofrequency Thermal Ablation of Implanted VX2 Liver Tumors in a Rabbit Model: Demonstration of Feasibility at 0.2 T. Magnetic Resonance in Medicine, 42, 141-149. http://dx.doi.org/10.1002/(SICI)1522-2594(199907)42:1<141::AID-MRM19>3.0.CO;2-I

[11] Lennon, D.P. and Caplan, A.I. (2006) Isolation of Human Marrow-Derived Mesenchymal Stem Cells. Experimental Hematology, 34, 1604-1605. http://dx.doi.org/10.1016/j.exphem.2006.07.014

[12] Hulspas, R. and Quesenberry, P.J. (2000) Characterization of Neurosphere Cell Phenotypes by Flow Cytometry. Cytometry, 40, 245-250. http://dx.doi.org/10.1002/1097-0320(20000701)40:3<245::AID-CYTO10>3.0.CO;2-5

[13] Schmitt, N., Calloe, K., Nielsen, N.H., Buschmann, M., Speckmann, E.J., Schulze-Bahr, E. and Schwarz, M. (2007) The Novel C-Terminal KCNQ1 Mutation M520R Alters Protein Trafficking. Biochemical and Biophysical Research Communications, 358, 304-310. http://dx.doi.org/10.1016/j.bbrc.2007.04.127

[14] Oh, S.H., Witek, R.P., Bae, S.H., Zheng, D., Jung, Y., Piscaglia, A.C. and Petersen, B.E. (2007) Bone Marrow-Derived Hepatic Oval Cells Differentiate into Hepatocytes in 2-Acetylaminofluorene/Partial Hepatectomy-Induced Liver Regeneration. Gastroenterology, 132, 1077-1087. http://dx.doi.org/10.1053/j.gastro.2007.01.001

[15] Gehling, U.M., Willems, M., Dandri, M., Petersen, J., Berna, M., Thill, M., Wulf, T., Muller, L., Pollok, J.M., Schlagner, K., Faltz, C., Hossfeld, D.K. and Rogiers, X. (2005) Partial Hepatectomy Induces Mobilization of a Unique Population of Haematopoietic Progenitor Cells in Human Healthy Liver Donors. Journal of Hepatology, 43, 845-853. http://dx.doi.org/10.1016/j.jhep.2005.05.022

[16] Natarajan, A., Wagner, B. and Sibilia, M. (2007) The EGF Receptor Is Required for Efficient Liver Regeneration. Proceedings of the National Academy of Sciences of the United States of America, 104, 17081-17086. http://dx.doi.org/10.1073/pnas.0704126104

[17] Paranjpe, S., Bowen, W.C., Bell, A.W., Nejak-Bowen, K., Luo, J.H. and Michalopoulos, G.K. (2007) Cell Cycle Effects Resulting from Inhibition of Hepatocyte Growth Factor and Its Receptor c-Met in Regenerating Rat Livers by RNA Interference. Hepatology, 45, 1471-1477. http://dx.doi.org/10.1002/hep.21570

[18] Yoshikawa, A., Kaido, T., Seto, S., Yamaoka, S., Sato, M., Ishii, T. and Imamura, M. (1998) Hepatocyte Growth Factor Promotes Liver Regeneration with Prompt Improvement of Hyperbilirubinemia in Hepatectomized Cholestatic Rats. Journal of Surgical Research, 78, 54-59. http://dx.doi.org/10.1006/jsre.1998.5350

[19] Buscarini, E., Savoia, A., Brambilla, G., Menozzi, F., Reduzzi, L., Strobel, D., Hansler, J., Buscarini, L., Gaiti, L. and Zambelli, A. (2005) Radiofrequency Thermal Ablation of Liver Tumors. European Radiology, 15, 884-894. http://dx.doi.org/10.1007/s00330-005-2652-x

[20] Choi, B.H., Kang, H.K., Park, J.S., Kim, S.K., Pham, T.N., Zhu, X.W., Cho, D., Nam, J.H., Chung, I.J., Kim, Y.J., Rhee, J.H., Kim, H.J. and Lee, J.J. (2006) Optimization of the Concentration of Autologous Serum for Generation of Leukemic Dendritic Cells from Acute Myeloid Leukemic Cells for Clinical Immunotherapy. Journal of Clinical Apheresis, 21, 233-240. http://dx.doi.org/10.1002/jca.20105

[21] Stute, N., Holtz, K., Bubenheim, M., Lange, C., Blake, F. and Zander, A.R. (2004) Autologous Serum for Isolation and Expansion of Human Mesenchymal Stem Cells for Clinical Use. Experimental Hematology, 32, 1212-1225. http://dx.doi.org/10.1016/j.exphem.2004.09.003 
Scientific Research Publishing (SCIRP) is one of the largest Open Access journal publishers. It is currently publishing more than 200 open access, online, peer-reviewed journals covering a wide range of academic disciplines. SCIRP serves the worldwide academic communities and contributes to the progress and application of science with its publication.

Other selected journals from SCIRP are listed as below. Submit your manuscript to us via either submit@scirp.org or Online Submission Portal.
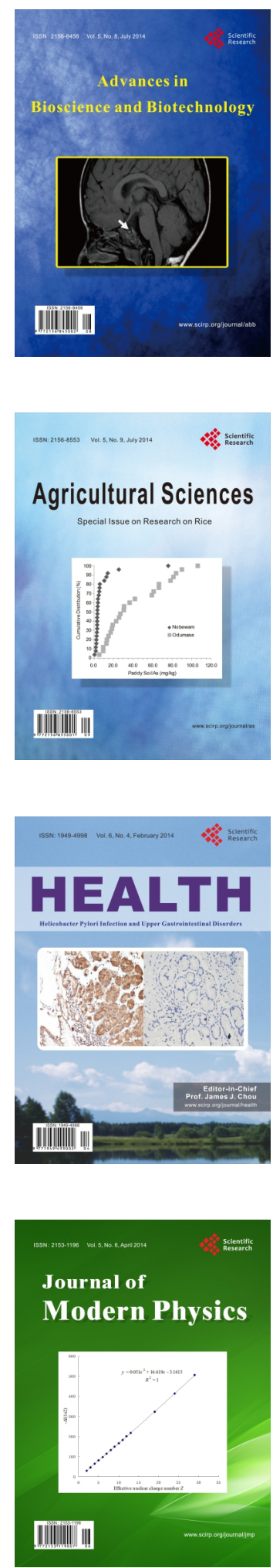
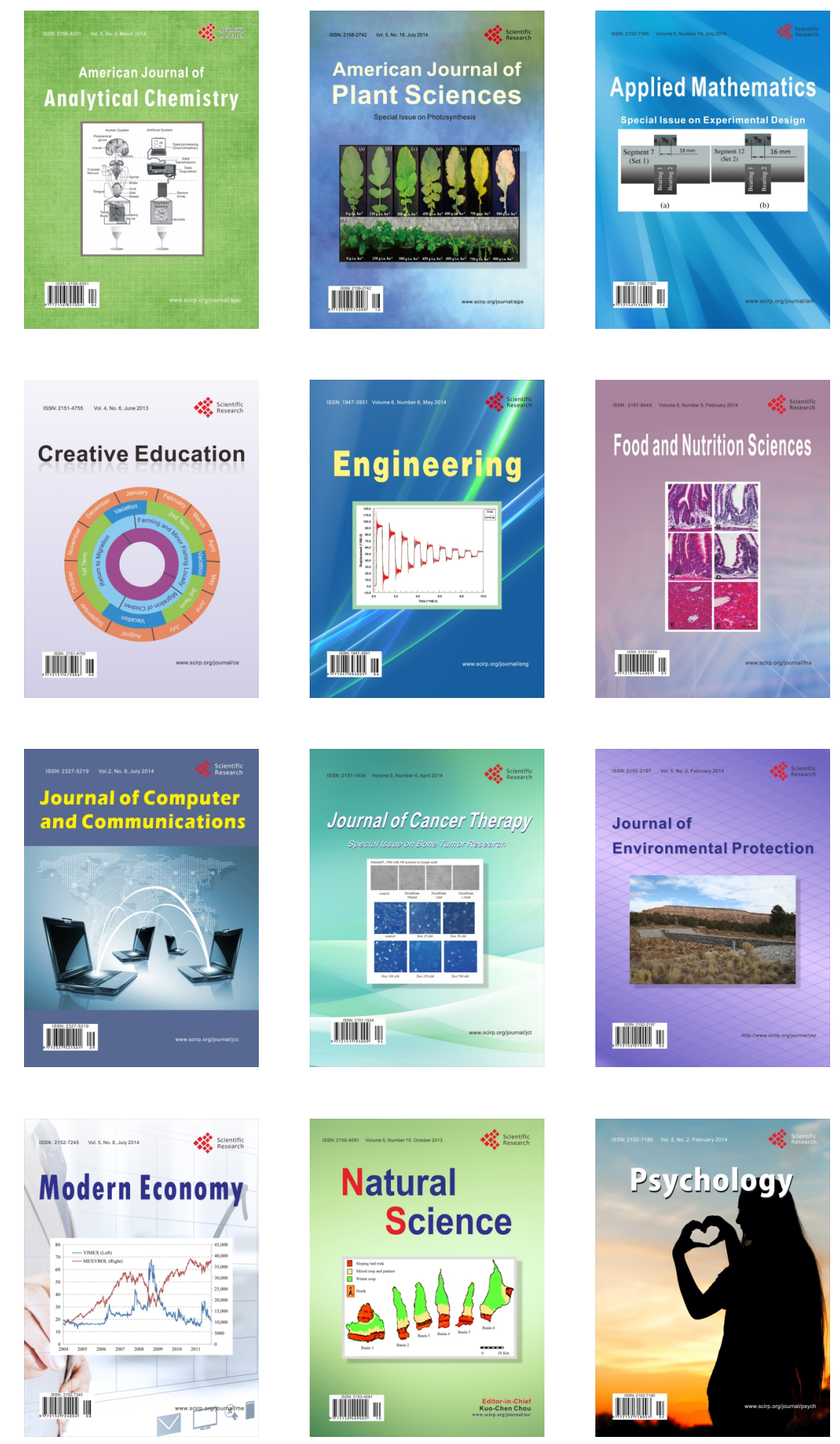